\title{
PROFESSORES DE LÍNGUA ESTRANGEIRA EM PRÉ-SERVIÇO: FATORES QUE INFLUENCIAM ESSA FORMAÇÃO
}

\begin{abstract}
Dieysa Kanyela Fossile é doutora em Linguística pela Universidade Federal de Santa Catarina. Pesquisadora e professora vinculada ao curso de Letras e ao Programa de Pós-Graduação em Ensino de Língua e Literatura da Universidade Federal do Tocantins. Coordenadora do Grupo de Estudos Metafóricos (GEM/UFT) e dos projetos de pesquisa: (a) "Metáforas: a leitura de textos metafóricos nas séries do ensino fundamental", (b) "Regularidade interpretativa: o significado aspectual na interpretação das sentenças metafóricas verbais do PB e do Inglês".

E-mail: dieysa@ibest.com.br; dieysa@mail.uft.edu.br.
\end{abstract}

Rosemeire Parada Granada Milhomens Costa é mestranda do Programa de Pós-Graduação em Ensino de Língua e Literatura da Universidade Federal do Tocantins. Integrante do Grupo de Estudos Metafóricos (GEM/UFT). Atualmente é professora vinculada ao curso de Letras do Centro Universitário Unirg. Desenvolve pesquisa sobre crenças e formação docente.

E-mail: meiregranada@yahoo.com.

Resumo: Neste artigo, temos como objetivo discutir alguns aspectos sobre $\mathrm{o}$ processo de ensino/aprendizagem de Língua Estrangeira e as principais teorias que fundamentam esse processo.
Abstract: In this article, we aim to discuss some central aspects concerning the Foreign Language teaching/learning process as well as the main theories behind this process.

\section{Introdução}

Neste artigo pretendemos desenvolver uma discussão a respeito da formação de professores de Língua Estrangeira (doravante LE). Para alcançarmos o objetivo pretendido, organizamos este texto em três seções. Na primeira seção, apresentamos um breve panorama sobre o ensino de LE. Na segunda seção, apresentamos uma abordagem sobre a formação de professores de LE, suas competências e crenças; e, por fim, na terceira seção, discutimos alguns aspectos concernentes às aulas de LE e às crenças sobre o bom professor de LE.

Filgueiras dos Reis (1992), externando sua preocupação quanto à formação de professores em pré-serviço, afirma que os cursos de formação de docentes podem não estar formando professores, mas treinando futuros instrutores. Preparar para a atividade docente é um exercício diário de reflexões sobre a própria práxis. Isto é, é preciso que o professor formador esteja consciente de que deve levar o professor em formação a refletir sobre a sua própria prática docente. Além disso, o professor formador deve levar o indivíduo em formação a perceber que não existe uma receita pronta para o ensino/aprendizagem de LE, que possa ser repassada, prontamente, pelo professor formador. Desse modo, é preciso pensar criticamente e refletir sobre o ensinar e sobre o porquê ensinar.

\section{1) Panorama sobre o ensino de LE: um breve histórico}

Durante e após a II Guerra Mundial, o ensino de LE começou a despertar interesse, principalmente pela necessidade de contato com aliados de outras origens e até mesmo com inimigos. A partir daí a necessidade do aprendizado de línguas tornou-se objeto de estudo. 
No momento em que o aprendizado de línguas passou a ser investigado, algumas teorias emergiram na tentativa de elucidar questões acerca do tema. Essas teorias sobre aquisição e aprendizagem de LEs passaram então a compor um importante campo de investigação dentro das ciências aplicadas, tendo a possibilidade de dialogar com outras áreas como Psicologia, Sociologia, Linguística, dentre outras, na tentativa de apresentar soluções no campo de desenvolvimento de línguas.

Dentre as teorias que desenvolvem estudos a respeito do ensino e da aprendizagem de LE, é possível citar, a princípio, as teorias Behaviorista, Cognitiva e Sóciointeracionista, tendo cada uma seus aspectos, as suas características e seus fundamentos.

Não poderíamos deixar de mencionar que Stephen Krashen merece destaque dentre os estudiosos que desenvolvem pesquisas a respeito do ensino e da aprendizagem de línguas. Krashen é um linguista e pesquisador renomado que nos trouxe vários estudos importantes sobre o assunto em questão. Dentre esses estudos, destaca-se a obra intitulada Natural Approach. Por meio dessa, na década de 80, Krashen nos apresenta o Modelo do Monitor (1982), possivelmente um dos mais conhecidos e discutidos modelos sobre o processo de aquisição e de aprendizagem de línguas. Dessa maneira, nos leva a refletir sobre cinco hipóteses:

$1^{\mathrm{a}}$ hipótese: distinção entre aquisição e aprendizagem;

$2^{a}$ hipótese: da ordem natural;

$3^{\text {a }}$ hipótese: do input;

$4^{\text {a }}$ hipótese: do Monitor;

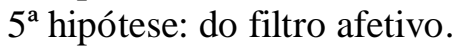

Essas hipóteses fundamentam a sua teoria e contribuem para que possamos compreender o processo de aprender uma LE ou adquirir uma Segunda Língua (L2).

E assim, neste cenário de constantes descobertas e experimentos acerca do desenvolvimento de uma LE, surgem a cada década novos pesquisadores e novas investigações com um único objetivo: colaborar com a prática dentro e fora de sala de aula no que tange ao ensino e aprendizado de línguas.

Segundo Leffa (1999), nosso país dá grande ênfase ao ensino de línguas, perpassando, historicamente, pelas línguas clássicas, grego e latim, desse modo, chegando às línguas modernas como o inglês, francês, alemão e italiano. Mas, com o passar dos tempos, essa história de apreciação de línguas diminuiu nas escolas. As Reformas pelas quais a Educação passou contribuiu para que ocorresse essa mudança e depreciação do ensino de línguas. Ao ensino de LE foi destinada uma carga horária mínima. Além disso, não era obrigatório apresentar frequência nas aulas de LE. Essa não obrigatoriedade era chamada de "frequência livre".

A Reforma Capanema de 1942, segundo Leffa (1992, p. 19), "ainda que criticada por alguns educadores como um documento fascista pela sua exaltação do nacionalismo, foi, paradoxalmente, a reforma que deu mais importância ao ensino de línguas estrangeiras".

Após essa Reforma, todos os alunos do ginásio até o científico estudavam as línguas modernas, chegando, alguns, a terminar o ensino médio lendo na língua-alvo e apreciando-a. O período ginasial compreendia a fase dos 11 aos 14 anos e o científico ou o clássico compreendia um período de 3 anos. O científico era voltado para as ciências exatas e o clássico para as humanas. Nos dias atuais, o ginásio corresponde ao período que vai do $6^{\circ}$ ao $9^{\circ}$ ano do ensino fundamental e o científico corresponde ao ensino médio. Nas palavras de Leffa (1999, p. 19) "vista de uma perspectiva histórica, as décadas de 40 e 50, 
sob a Reforma Capanema, foram os anos dourados das línguas estrangeiras no Brasil". Em seguida, com a publicação da LDB em 1961, essa era dourada vê o seu fim se aproximando com a redução da carga horária das LEs a 2/3 do que antes fora. Dez anos mais tarde, com a LDB de 1971, instituiu-se o ensino como sendo profissionalizante, tornando-se assim, segundo o Conselho Federal, a LE dada por acréscimo. Mais tarde, em 20 de dezembro de 1996, é publicada a nova LDB que apresenta a obrigatoriedade do ensino de uma LE, de acordo com as necessidades de cada região, a qual será escolhida pela comunidade escolar.

Atualmente, estão sendo publicados os Parâmetros Curriculares como complementação para a nova LDB, que sugerem uma abordagem sócio-interacionista para o ensino da LE com ênfase na leitura, acreditando ser esta a habilidade mais necessária para os jovens estudantes, uma vez que os mesmos buscarão inserção no mercado de trabalho futuramente.

Enfim, apresentado o cenário acima, podemos ainda acrescentar que vivemos em uma época onde o contato entre línguas nunca se fez tão importante e intenso. O papel da necessidade de uma LE já não necessita de tantas explicações, visto a ampliação de contato entre diferentes povos e culturas. Também podemos verificar que os professores são responsáveis por parte deste processo de ensino e aprendizagem de LE. Esses professores são fundamentais nesse panorama, pois são em grande parte incentivadores da aprendizagem. Mas cabem aqui os questionamentos: como estão sendo formados esses futuros profissionais? Os saberes desses professores em pré-serviço estão sendo lapidados através de teorias que fundamentam o processo de ensino e aprendizagem de uma LE? Acreditamos caber aos cursos de formação, como já dito anteriormente, o importante papel de mostrar a esses professores em formação o todo de sua práxis, mostrar que são necessárias reflexões críticas que possam favorecer seu desenvolvimento profissional.

\section{2) Formação de professores de LE: suas competências e crenças}

$\mathrm{Na}$ escola e na sala de aula, podem ocorrer trocas de experiências entre alunos, professores e comunidade. Segundo Guimarães (2006, p. 31-32), esse é

[...] um espaço de mediação entre o aluno e a cultura, envolvendo processos intensos de relações [...]. A atividade profissional do professor pode ser caracterizada como uma atividade de mediação não só entre o aluno e a cultura, mas também entre escola, pais e alunos, Estado e comunidade etc. Esse caráter de mediação, no caso, entre governo e sociedade, inerente ao trabalho do professor, justifica os investimentos de organismos diversos na configuração de uma identidade do professor na sociedade.

Os professores que atuarão no ensino de LEs devem ser preparados para desenvolverem um ensino com qualidade; além disso, não podemos ignorar o fato de que muitos já trazem suas crenças a respeito do ensino de LE, as quais, muitas vezes, influenciam no seu próprio trabalho. Portanto torna-se responsabilidade dos professores formadores mostrar que o fazer do professor de LE e a sua prática pedagógica devem estar baseados em intuições, mas também em teorias e competências.

Para exemplificarmos o parágrafo precedente, citaremos um exemplo que observamos nas aulas de LE, do curso de Letras, de uma universidade privada do município de Gurupi (TO). Isto é, verificamos que nas aulas de LE, na formação pré- 
serviço, é bastante comum o professor formador ser questionado sobre a prática de atividades de tradução. Em outras palavras, os professores formadores são questionados principalmente quando as atividades de tradução de textos ou de frases ou de palavras não são praticadas nas aulas de LE. Verificamos que os professores em pré-serviço acreditam que, através dessas atividades, aprenderão a língua. Com base nessa observação, julgamos que este é um exemplo clássico de crença que é trazida para as licenciaturas em Letras, pois é do senso comum e faz parte da cultura popular de que esta é uma maneira eficiente para o aprendizado/aquisição da LE. Também julgamos que o papel do professor formador se torna imprescindível neste momento. É necessário tentar desmistificar essa crença apresentando teorias, estudos e metodologias que apontem para outras formas de ensino/aprendizagem de línguas. Dessa maneira, cabe ao professor formador conduzir o fazer pedagógico do futuro profissional para que o mesmo seja embasado por teorias e competências; e, não, apenas por intuições e/ou crenças trazidas do seu meio social ou de suas experiências anteriores.

Almeida Filho (2006, p. 11) elenca cinco competências que, segundo o próprio autor, são "um construto teórico que se compõe de bases de conhecimentos informais (crenças), de capacidade de ação e deliberação sobre como agir na sala de aula", sendo elas: (1) competência implícita, (2) competência linguístico-comunicativa, (3) competência teórica, (4) competência aplicada (subcompetência teórica) e (5) competência profissional.

Dessa maneira, Vieira-Abrahão (2001) apresenta um modelo proposto por educadores noruegueses, Handal e Lauvas, no qual é abordado que "três fontes das teorias práticas do professor são delineadas: a experiência pessoal, o conhecimento transmitido e os valores pessoais." Já Cardoso (2001, p. 90) discute que o "ensinar está sujeito a grandes pressões de rotinização, rotinas essas protetoras e mantenedoras de papéis, com um efeito anestésico sobre o senso de plausibilidade (grifo do autor) do professor" e aponta ainda que senso de plausibilidade pode ser considerado como intuição para ensinar, um feeling pedagógico. Ainda, na mesma linha, Almeida Filho, discutindo sobre a formação dos professores de LE em uma palestra apresentada em Palmas-TO durante um encontro da Aplitins (Associação dos professores de língua inglesa do Tocantins) no ano de 2009, cita um fazer mágico que acontece na sala de aula quando o professor obtém êxito em determinada aula, mas não sabe ao certo reconhecer como e quando algo funcionou e nem o que fazer para tornar a dar certo. Bordieu (apud Blatyta, 2000, p. 64) sugere que alguns professores "[...] estão predispostos a agir de certo modo, perseguir certos objetivos, aprovar certos gostos, etc., por virtude do habitus [...]".

Entendemos que somente o habitus, o fazer mágico, o feeling e as experiências pessoais não são suficientes para se executar um bom trabalho docente. Julgamos, a partir dos estudos e leituras desenvolvidos, que é necessário um aprofundamento na questão da abordagem, a qual, segundo Almeida Filho (2007, p. 17), “[...] equivale a um conjunto de disposições, conhecimentos, crenças, pressupostos, e eventualmente princípios sobre o que é linguagem humana, LE, e o que é aprender e ensinar uma língua-alvo". O autor acrescenta ainda que a abordagem pode ser compreendida como "uma filosofia, um 
enfoque, uma aproximação, um tratamento, uma lida" (2007, p. 18). Com base em Almeida Filho, compreendemos que abordagem é a maneira como o professor trabalha o conteúdo em sala de aula utilizando teorias tanto implícitas quanto explícitas. Isto é, compreendemos que "todo professor de LE (ou de outras disciplinas, com os devidos ajustes) constrói um ensino (um processo de ensinar)" (2007, p. 18).

\section{1) A questão das competências}

Conforme abordamos no final da seção precedente, um professor deve carregar consigo a sua abordagem de ensino, a qual irá determinar a sua maneira de agir enquanto docente. Almeida Filho (2007, p. 20), ao discorrer sobre as concepções de linguagem, pontua que o ato "de aprender e ensinar uma língua-alvo, se mantém com a matéria prima das competências dos professores", e nos apresenta duas das competências elencadas como necessárias para a formação do professor de LE, isto é, a competência implícita e a competência linguístico-comunicativa.

O autor aborda que a competência mais básica é a implícita, que é constituída de intuições, crenças e experiências. Almeida Filho (2007, p. 20) afirma que "quando o professor já possui uma competência linguístico-comunicativa, ou seja, se comunica de forma satisfatória na língua-alvo, está apto para operar em situações de uso da LE, assim sendo, ele já pode ensiná-la num sentido básico ou tosco de ensinar".

A competência implícita é influenciada por experiências vividas. Muitas vezes, nós tomamos nossos próprios professores como exemplo para desenvolvermos a nossa própria prática de ensino. Quer dizer, a maneira como fomos ensinados também influencia na nossa prática de ensino; a partir daí, inferimos conceitos do que seja ensinar uma LE, selecionamos e elaboramos atividades para trabalhar em certos momentos. Além disso, carregamos certas marcas deixadas por alguns de nossos professores e muitas dessas marcas, quando positivas, procuramos repassar aos nossos alunos. Dessa maneira, palavras ou modos de ensinar são influências que, muitas vezes, derivam das práticas de professores que passaram por nossas vidas. É dessa forma que tentamos construir a nossa própria maneira de ensinar, a qual também poderá influenciar outros educadores e professores em pré-serviço no seu modo de ensinar e/ou aprender.

Quanto à competência linguístico-comunicativa, temos um fator importante a ser considerado no que tange à formação pré-serviço em LE. Devemos ter o cuidado de mostrar a esses indivíduos em formação que o propósito ao qual se destinam nos cursos de licenciatura em Letras, sejam eles habilitação única ou dupla ${ }^{1}$, é o de se formarem

\footnotetext{
(a) Trata-se da modalidade cuja estrutura tem o propósito de preparar o futuro professor de Língua Portuguesa e de suas respectivas literaturas, para o exercício do magistério na Educação Básica, trabalhando assim um conjunto de disciplinas, estágios e demais atividades acadêmicas voltadas ao trabalho de formação profissional. (b) Trata-se da modalidade dupla cuja estrutura também tem o propósito de preparar o futuro professor para o exercício do magistério na Educação Básica por meio de disciplinas, estágios e demais atividades acadêmicas, mas que oferece além da Língua Portuguesa e de suas respectivas literaturas uma língua estrangeira (Inglês, Espanhol, Francês dentre outras, dependendo da instituição de ensino).
} 
professores de LE e não falantes fluentes da mesma língua. O fazer docente é mais que simplesmente habilidade comunicativa. O ofício de se ensinar LE requer outras habilidades. É necessário enxergar a LE, neste caso, como destinada a um fim específico, o ensino.

Vemos nas licenciaturas em Letras um grande problema quanto a esta questão linguístico-comunicativa. Constatamos que os nossos licenciandos, mais uma vez, arraigados por crenças, acreditam que o curso de Letras os levará à fluência comunicativa, desconhecendo muitas vezes o propósito real da licenciatura que é o de formar professores capacitados a utilizar a LE em situação de ensino. Essa situação os frustra, levando-os a enraizar uma das crenças mais comumente apresentadas por professores em pré-serviço, a da impossibilidade de serem bons professores de LE por não serem "fluentes" na língua.

Ao longo dos nossos estudos, compreendemos que um professor, especialmente um professor de LE, precisa de modelos para operar em sua área de conhecimento até que alcance uma abordagem desejável e consciente. Nesse caso, novamente, nos apoiamos em Almeida Filho (2007, p. 21), que nos apresenta a terceira e a quarta competência, as quais estão interligadas. Segundo o autor,

[...] o professor necessita desenvolver uma competência aplicada. A competência aplicada (grifo nosso) é aquela que capacita o professor a ensinar de acordo com o que sabe conscientemente (subcompetência teórica) (grifo nosso) permitindo a ele explicar com plausibilidade porque ensina da maneira como ensina e porque obtém os resultados que obtém.

Percebemos que um professor de LE, para alcançar o topo da consciência profissional, precisa desenvolver a competência profissional. A competência profissional é a responsável para que o professor administre sua profissão e seu próprio crescimento como educador de línguas, para que assuma seu papel como participante no meio social através do exercício do magistério (Almeida Filho, 2007).

Concordamos, em partes, com o autor, pois julgamos que a tomada de consciência por parte do professor para alcançar o aperfeiçoamento dessas competências é essencial para que a atividade docente aconteça de maneira satisfatória. Porém, avaliamos que vários fatores, os quais fogem da vontade do professor, em determinados momentos, interferem nesse mecanismo. Isto é, em alguns casos, os professores formados ou em formação esbarram em fatores diversos como: o financeiro, a sobrecarga de trabalho, entre outros, dificultando e atrasando a efetivação desse aperfeiçoamento. Porém, mesmo tendo alcançado o nível final das competências, devemos considerar que a abordagem do professor não pode ser a única influência para que o processo de ensino e aprendizagem ocorra em sala de aula. Envolvidos neste processo, temos que lidar com uma série de fatores que permeiam essa via de duas mãos que é o ato de ensinar e aprender. O professor

(Disponível em: http://www.letras.ufpr.br/graduacao/opcoes_de_cursos/modalidades.html. Acesso em: 05 de outubro de 2012). 
tem que contar ainda, dentro desse panorama, com fatores internos e externos os quais podem afetar a sua aula.

Almeida Filho (2007) destaca dentre os fatores internos, o filtro afetivo, tanto do professor quanto do aluno, o qual envolve motivações, frustrações, ansiedades, cansaço, pressões do grupo, entre outras questões. $\mathrm{O}$ autor cita como um dos fatores externos o próprio material didático, que julgamos ser um aliado e também um entrave, dependendo do contexto em que o professor trabalha. Ele ainda apresenta outros elementos com os quais o professor tem que se relacionar como:

[...] a abordagem de aprender do aluno, a abordagem de ensino subjacente ao material didático adotado e os valores desejados por outros no contexto escolar (a própria instituição, o diretor, os outros professores líderes, com maior antiguidade e/ou maior poder dentro do corpo docente. (Almeida Filho, 2007, p. 23).

\section{2) A questão das crenças}

O processo de preparar para a tarefa de ensinar uma LE deixou de ser uma questão meramente técnica e passou a adotar uma linha construtivista e reflexiva. Através da linha construtivista e reflexiva se deve tentar despertar nos professores em pré-formação as competências básicas, teóricas e profissionais para a atuação em sala de aula. De acordo com Barcelos e Abrahão (2006, p. 43), entendemos que "a formação profissional deixa de ser vista como treinamento e passa a ser entendida como o conjunto das estratégias que facilita a reflexão [...]". A preocupação com a formação inicial de professores, sobretudo a formação de professores de LE, vem sendo um assunto de grande relevância no âmbito educacional, e tem se tornado objeto de diversos estudos e gerado várias publicações a respeito (Celani, 2002; Almeida Filho, 2005; Barcelos e Abrahão, 2006; Teles, 2009). Esse número crescente de estudos sobre a formação de professores de línguas mostra ainda a inquietação de linguistas em entender como esses futuros profissionais estão sendo preparados para sua ação docente.

As experiências adquiridas ao longo de todo processo de formação na educação básica são trazidas para o ensino superior e devem ser analisadas e trabalhadas de modo a não interferirem negativamente na formação docente desses professores em pré-serviço. As experiências de como se aprende uma LE estão na memória desses indivíduos baseados em modelos adquiridos na sua experiência escolar e que podem influenciar na sua prática acadêmica. Barcelos e Abrahão (2006, p.43) destacam o seguinte questionamento: "Os saberes da prática são os saberes dos professores ou são suas teorias pessoais?"

Para responder a essa questão, podemos recorrer às aulas de prática de ensino de LE. Durante a observação de aulas de LE, verificamos que os modelos adquiridos na experiência escolar aparecem durante o processo de preparação de aulas a serem ministradas pelos próprios professores em pré-serviço. As experiências vivenciadas pelos professores em pré-serviço, quando positivas, interferem fortemente nas suas próprias aulas, as quais são por eles planejadas e posteriormente aplicadas. Como já salientamos em 
outros momentos deste texto, a questão da interferência de modelos adquiridos não representa descrédito ao processo de formação pré-serviço, pelo contrário, até faz parte dele, desde que o professor formador aproveite estas oportunidades para subsidiar seus alunos com suporte teórico suficiente para que eles sejam capazes de discernir o porquê fazem dessa ou daquela maneira e não simplesmente copiem modelos anteriores como "receitas prontas" que já funcionaram no passado com eles enquanto aprendizes.

Nas últimas duas décadas, os estudos sobre a formação docente vêm dando ênfase cada vez mais para o aspecto das crenças. O interesse pelo conhecimento de crenças, conforme Barcelos e Abrahão (2006, p.105), surgiu em meados de 80, no exterior, e em meados dos anos 90, no Brasil, tendo então se tornado base de discussões no campo da Linguística Aplicada e temas de vários trabalhos dissertativos (Garbuio, 2005; Silva, 2005, dentre outros).

O termo crenças não é assim tão facilmente conceituado por envolver uma série de outras denominações que nos remetem à ideologia, a representações, dentre outras questões. Silva (2011), citando os estudos de Woods (1996), se utiliza da metáfora "floresta terminológica" para se referir às crenças, devido à complexa tarefa de defini-la. De acordo com Barcelos e Abrahão (2006), as crenças podem ser definidas, no cotidiano, em vários sentidos. Assumimos, neste artigo, o conceito de crenças de Barcelos (2006, p. 01):

[...] as crenças têm suas origens nas experiências e são pessoais, intuitivas e na maioria das vezes implícitas. Dessa forma, as crenças não são apenas conceitos cognitivos, mas são socialmente construídas sobre experiências e problemas, de nossa interação com o contexto e da nossa capacidade de refletir e pensar sobre o que nos cerca.

No decorrer dos estudos realizados, verificamos que há influência das crenças na formação de professores em pré-serviço. As crenças permeiam essa formação e, muitas vezes, os professores em pré-serviço julgam os seus modelos de aprender como os modelos que devem ser seguidos no ensinar. Concordamos que a competência implícita tem seu valor, pois a ela é dado o crédito da motivação e da vontade de ensinar, mas devemos novamente salientar que o objetivo máximo a se atingir deve ser a competência profissional e, para tanto, devemos guiar esses futuros professores a refletirem sobre suas próprias crenças de maneira a perceberem que há fatores ligados às suas crenças pessoais que acarretam problemas para sua formação profissional.

Nas aulas de LE, observamos que, quando os professores em pré-serviço são questionados sobre a melhor idade para se aprender línguas, a resposta imediata apresentada é: na infância. Eles acreditam que a criança ainda não tem acúmulo de preocupações na cabeça e, por isso, elas aprendem línguas rapidamente. Notamos que tentam justificar e/ou explicar a dificuldade de desenvolvimento de uma LE em adultos, argumentando que as preocupações diárias atrapalham o aprendizado de LEs. Podemos inferir dessa resposta duas questões: (a) a crença da melhor idade para se aprender uma LE é uma máxima do conhecimento popular, (b) a explicação para suas próprias dificuldades 
enquanto aprendizes advém do fator "idade", justificando-se, assim, outra crença, a de que aqueles que iniciam os estudos de LE ainda na infância têm melhores possibilidades de serem "bons" professores da língua em questão.

Barcelos e Abrahão (2006) respaldam o parágrafo precedente quando discutem que as crenças são moldadas e circunstanciadas tanto culturalmente quanto historicamente. As autoras afirmam que "embora tenham caráter subjetivo e, portanto individual, as crenças são construídas socialmente, tendo no social, no grupo, sua origem e manutenção. Normalmente, são formadas muito cedo em nossas vidas e por essa razão tendem a ser resistentes às mudanças" (2006, p. 71).

Portanto, a partir das leituras e estudos desenvolvidos, concluímos que as crenças podem ser entendidas como entidades dinâmicas, interativas e socialmente construídas (Kalaja, 1995, 2004; Barcelos, 2000, 2004; Conceição, 2004). Partimos do pressuposto de que muitos professores em pré-serviço apresentam uma ideia do que seja um bom professor de LE, do que seja uma boa aula de LE. Muitos se baseiam em conceitos formados pela sociedade e o meio em que vivem. Muitos acabam não levando em consideração fatores que são apontados pela literatura e que são de grande importância para essa formação. Percebemos, no decorrer dos nossos estudos, que as crenças são mutáveis, podendo ser transformadas ao longo do período de formação; dessa maneira, não somos totalmente a favor da afirmação das autoras acima, que abordam que as crenças são resistentes às mudanças. Porém, temos ciência, a partir das observações que fazemos em nossas próprias aulas, que é uma mudança que ocorre lentamente. Dessa maneira, ressaltamos que pesquisas atuais sobre crenças de aprendizado de línguas, no campo da Linguística Aplicada, mostram que a formação de futuros docentes de LE está cercada por crenças. Algumas dessas crenças que rondam esse cenário educacional não são facilmente desmistificadas, pois trazem uma forte carga cultural, o que facilita a criação das mesmas, fazendo com que perdurem por décadas e permeiem a formação de alunos e de profissionais em pré-serviço.

Conforme já abordado precedentemente, ao mesmo tempo em que julgamos que as crenças são passíveis de mudanças e transformações, verificamos, nas próprias aulas de LE, que essas mudanças acontecem de forma lenta. E essa lentidão acaba tornando a prática do professor repetitiva e às vezes sem ação efetiva perante os professores em préserviço; dessa maneira, acabamos permitindo que as crenças desses professores sejam enraizadas e perpetuadas. É preciso desmistificar, investigar e analisar que ideologias sustentam determinadas crenças ou aglomerados de crenças, que são as ramificações dessas crenças, e o impacto que elas podem ter na formação desses professores em préserviço. Essa não é uma tarefa fácil, pois lidamos a todo momento com indivíduos únicos e, portanto, com histórias únicas. Barcelos e Abrahão (2006, p. 119) destacam que mapear com exatidão as origens das crenças trazidas pelos professores de língua em pré-serviço é uma missão difícil, senão impossível. Mas a nosso entender, estudar as bases que fundamentam essas crenças se faz necessário uma vez que buscamos entender e aprimorar o processo de formação desses indivíduos. É preciso avaliar as produções verbais desses 
futuros profissionais para esclarecer que impactos elas podem causar na sociedade e nas salas de aula, que são um reflexo da sociedade.

A partir dos estudos realizados e discutidos neste artigo, questionamos: seriam essas crenças que circulam pela formação de professores, além de culturais, provenientes de políticas educacionais que não encorajam um estudo mais reflexivo da LE? Talvez sim, mas são inúmeros os fatores que poderíamos relacionar como fonte de estudo dessas crenças, entre eles: a falta de valorização da profissão e a falta de valorização dos cursos de Letras. Os próprios acadêmicos dos cursos de Letras incorporam a crença de que escolheram uma profissão fadada ao desgaste, senão ao fracasso. Outro exemplo são os vários acadêmicos que frequentam o curso de Letras - PARFOR (Plano Nacional de Formação de Professores da Educação Básica) da Universidade Federal do Tocantins, do campus de Araguaína. Esses acadêmicos, na grande maioria, são professores que atuam na rede pública ou privada do Estado do Tocantins e, em seus depoimentos, durante as aulas presenciais, demonstram grande descontentamento com o(s) curso(s) de licenciatura e com a profissão. Como aponta uma pesquisa em Barcelos e Abrahão (2006, p.117), "a imagem do curso de Letras entre os próprios alunos do curso não é das melhores. A maioria deles cita que o curso de Letras é um curso fraco, sem nenhum reconhecimento, cujos alunos não são inteligentes para ingressarem em outros cursos mais concorridos". E temos ainda como consequência disso aqueles que se apegam a crenças de que ser professor de inglês não é tarefa para eles, talvez pela ideia que tenham dessa língua baseados em experiências anteriores, e tentando assim tornar verdadeira a crença da língua inatingível, focando seus estudos na outra habilitação do curso, Língua Portuguesa, se eximindo assim no futuro de qualquer culpa quando fracassarem como professores de LE.

Avaliamos que o despreparo dos profissionais de LE se deve em grande parte às crenças que mistificam a aprendizagem de LE e a tornam algo inatingível mesmo antes que esses professores em pré-serviço possam aprofundar seus conhecimentos na e sobre a mesma.

As crenças exercem influência no não-fazer, onde [...] poucas ações são realizadas para promover o desenvolvimento efetivo de uma proficiência desejada na aprendizagem de LE. Em geral, os alunos adotam uma atitude passiva (entre outras razões, porque não sabem fazer diferente) de não engajamento na tarefa de aprender línguas (Almeida Filho, 2005, p. 174).

Almeida Filho (2005, p.159) sugere que é importante lembrar que cada sociedade faz uma leitura do quê, como e para quê se deve aprender uma LE e prossegue:

Essa leitura acontece diariamente nas conversas entre membros de um mesmo grupo e de uma mesma profissão. Professores e alunos possuem seus hábitos, costumes e expectativas sobre aprendizagem de língua estrangeira que são sustentados e legitimamente aceitos na sociedade. 
A mesma leitura, como referido acima, deve ser feita diariamente nas salas de aula que formam professores. É importante que formadores de professores de LE tenham uma ideia clara de quais crenças seus alunos trazem para os bancos universitários, quais as mais influentes, aquelas que sobretudo podem, de maneira significativa, interferir nesse processo de formação, positiva ou negativamente. Enfim, a formação de professores se apresenta em um panorama de interesse nacional e internacional de pesquisas. É preciso que os formadores e os formandos ajam de uma maneira crítico-reflexiva, reflitam sobre as suas próprias abordagens de ensino e sobre as suas próprias crenças buscando um caminho que leve a um ensino mais efetivo de LE.

\section{3) O bom professor de LE e considerações finais}

Diante do exposto nas seções anteriores, é necessário observarmos as aulas de LE para avaliarmos onde estamos com relação ao processo de ensino e aprendizagem de LE. Almeida Filho (2005, p.19) traça, em poucas palavras, o atual panorama de ensino de LE no Brasil:

A grande maioria das classes de língua estrangeira nas escolas públicas, que equivale à base de sustentação profissional na área de ensino, e praticamente todos os livros didáticos nacionais à venda no momento enfatizam a aprendizagem consciente das formas da língua combinada com exercícios de automatização de modelos [...], o grande pressuposto é o de que o domínio da forma (gramatical e do léxico) levará por extensão ao uso normal da língua-alvo.

Estudos como o de Barcelos e Abrahão (2006) e Almeida Filho (2006), aqui já mencionados, se preocupam com a formação de futuros profissionais da área de ensino de LE e com as crenças que esses profissionais em pré-serviço trazem consigo durante sua formação acadêmica. Os autores apontam que a boa formação acadêmica é um quesito fundamental para a tentativa de mudança dessa situação concernente à formação de professores de LE. Sobre a questão da formação acadêmica e da boa aula de LE, podemos citar Prahbu (1992). O autor discute que a sala de aula não deve ser considerada apenas como um espaço físico para exercer a atividade de ensino/aprendizagem, mas deve ser entendida como um espaço onde conjuntos de ideias são trabalhados para atingir os núcleos que compõem uma sociedade, como a família, os amigos, as classes de pesquisadores e os estudiosos; para isso é necessário que o futuro profissional tenha uma formação acadêmica crítica e reflexiva.

Segundo Cardoso (2001, p. 82), "os acontecimentos ocorridos em sala de aula envolvem indiretamente aqueles ligados aos dois sujeitos principais da sala de aula, professor e aluno", ou seja, tudo ou quase tudo aquilo que se aplica em sala é mais tarde desenvolvido, desempenhado em sociedade. O referido autor prossegue afirmando que "as atividades escolares, boas ou más, refletem fora da escola, tornando a aula, uma arena de 
interação humana, onde os insumos aplicados são fatores determinantes para o desenvolvimento ou não dessa experiência de crescimento que é a sala de aula".

Levando em conta o que foi discutido acima, consideramos que uma aula de LE é também uma arena de pluralidade cultural, onde comparações sobre tradições, costumes e gostos são inevitáveis para o próprio desenvolvimento da aula. Nesse tipo de aula, não só o aluno desenvolve suas capacidades cognitivas, mas também o professor, pois o mesmo tem que adaptar suas técnicas, seus métodos e abordagens, adequando-os aos moldes da turma. Dessa forma, entendemos que as competências e abordagens seguidas pelo professor não são as únicas responsáveis pelo sucesso ou não de uma aula, isto é, compreendemos que há os fatores motivacionais e interacionais que envolvem professores e alunos. Perrenoud (2000) aponta algumas características como sendo as novas competências de ensinar, dentre elas: (a) estar aberto a aprender, (b) ser dinâmico e (c) ser criativo. Quando a temática central de uma discussão é o bom professor de $L E$, essas características deveriam ser discutidas e abordadas. Conforme Barcelos e Abrahão (2006, p. 71), muitos professores em pré-serviço idealizam que, para se atingir o grau de bom profissional de LE, deve-se ter fluência na língua-alvo, negligenciando, dessa maneira, todas as outras habilidades pertinentes ao profissionalismo de um docente de LE, como a criatividade, o planejamento, o entusiasmo, o conhecimento teórico, dentre outras questões.

Nas aulas de LE, verificamos que são inquietantes as discussões que dizem respeito às crenças do bom professor de LE. É possível observar, ainda que a passos lentos como citado anteriormente, algumas mudanças com relação a essas crenças. Ao mesmo tempo em que os professores em pré-serviço acreditam na competência linguística como fator sine qua non para o bom trabalho do docente de LE, dão também ênfase aos fatores afetivos entre professor e aluno. Constatamos nessas discussões, que são realizadas nas aulas de LE, expressões metafóricas nas falas dos professores em pré-serviço, pois esses futuros profissionais tentam explicar o que é ensinar uma LE e o que é ser um bom professor de LE utilizando metáforas. Dentre as falas observadas, citamos: (a) o professor de LE deve encantar seus alunos com sua disciplina; (b) o professor de LE deve impor respeito, mas sempre com doçura; (b) o professor de LE deve ser amigo e levar os alunos a viajarem na disciplina com ele. Concluímos que, por meio do uso de metáforas, tais como as observadas e aqui apresentadas, os futuros professores tentam conceituar uma boa aula de LE e criar um perfil para um bom professor de LE. Levando em consideração as discussões realizadas nas aulas de LE e as expressões metafóricas observadas durante as discussões, ressaltamos os estudos de Cortazzi e Jin (1999), de Rebecca Oxford e colaboradores (1998) que também estudam e discutem o uso de metáforas relacionadas ao professor, isto é, ao seu trabalho e a como os alunos o vêem. (cf. Sardinha, 2012, p. 63 $85)$.

Obviamente, como já mencionado, essa mudança é lenta e pesquisas atuais nos revelam que algumas crenças ainda permeiam a formação pré-serviço e são difíceis de serem desmistificadas. Barcelos e Abrahão (2006) desenvolveram uma pesquisa com cento 
e trinta e nove sujeitos, tendo como objetivo identificar as crenças sobre a aprendizagem de línguas dos alunos que já ingressaram no curso de Letras. A partir daí

[...] os resultados advindos da triangulação dos dados evidenciaram duas crenças fortes em relação a aprendizagem de línguas: primeira: a crença de que a criança aprende com mais facilidade do que o adulto, a segunda e última: a estadia e permanência no país onde se fala a língua alvo como condição sine qua non para aprendizagem de LE (Barcelos e Abrahão, 2006, p. 109).

No Brasil, estamos cercados por escolas de idiomas que se destinam a ensinar o que deveria ser aprendido nas escolas regulares. De certa forma, há uma série de fatores que contribuem para que este ensino não aconteça. Essas mesmas escolas têm em seu quadro de professores profissionais com fluência na língua-alvo, mas que nem sempre ou quase nunca são formados nos cursos de Letras. Esses profissionais, muitas vezes, são chamados de bons professores de língua estrangeira, mas esses professores, na maioria das vezes, têm pouco ou nenhum conhecimento teórico. Além disso, eles têm pouca ou nenhuma prática didático-pedagógica, o que torna também algumas aulas nesses cursos de idiomas tediosas, gramatiqueiras.

Aos cursos de graduação em Letras cabe o importante papel de mostrar aos professores em formação o todo de sua práxis, o porquê ensinamos, como ensinamos e como aprendemos. São necessárias reflexões críticas que possam favorecer o desenvolvimento dos futuros profissionais do ensino de LE. É preciso esclarecer para os professores em pré-serviço que não se deve simplesmente crer que o domínio da competência linguística seja capaz de efetivar, sozinho, um bom desempenho docente. Para Silva (2005), muitos professores deixam as universidades e chegam às salas de aula com pouca experiência didático-pedagógica, além de estarem permeados por crenças. É preciso mostrar a esses professores em pré-serviço que a teoria que até então era informal agora abre espaço para teorias fundamentadas, de que a crença de um falante fluente não basta para sustentar um bom trabalho em LE, e que, a exemplo disso, temos vários falantes de LE que não conhecem a gramática da língua que falam e, portanto, não sabem ensiná-la.

Qualquer que tenha sido o método usado pelos nossos professores quando começamos a aprender uma língua estrangeira, ele tenderá a se transformar na maneira "natural" de aprender línguas. Essa é a manifestação básica de um princípio pelo qual, na ausência de uma postura bem fundamentada e crítica sobre o aprender línguas, fazemos o que vimos ser feito conosco ou ao nosso redor. A teoria informal de aprender e ensinar faz parte de um quadro referencial organizado de memórias, percepções, crenças e atitudes sobre esse tipo de problema. (Almeida Filho, 2005, p. 19).

O processo de formação inicial de professores pode influenciar a futura conduta docente, bem como a imagem que esse futuro profissional venha a ter de si mesmo como professor. Para Pow (2003, p.79) “(...) a comparação com um modelo "ideal” frequentemente representado pela figura do inquestionável falante nativo da língua inglesa 
- reflete na maneira como esses profissionais se percebem como professores [...]." Assim, conhecer e interpretar essas crenças pode ser um caminho para a possibilidade de mudanças na formação de profissionais atuantes nesta área. Consideramos que os professores em pré-serviço tendem a criar um modelo perfeito de professor de LE, como cita Barcelos (2001, p. 72), através de "idéias, opiniões e pressupostos que alunos e professores têm a respeito dos processos de ensino/aprendizagem de línguas e que os mesmos formulam a partir de suas próprias experiências", modelo esse que nunca serão capazes de alcançar. Fernandes (2006) aponta para o fato de que os professores já formados e os em formação também abrem mão de construir sua própria imagem profissional por se compararem a um modelo cultural e socialmente aceito como ideal.

Mas qual seria o perfil ideal de um professor de LE? Seria possível criar um modelo de professor baseado somente em crenças, julgamentos, conceitos e até préconceitos sobre qual a imagem ideal de um professor de LE?

Os questionamentos acima podem apresentar respostas diferentes dependendo do contexto em que se apresentam. Neste trabalho em particular, nos fundamentamos em três pilares teóricos para que pudéssemos apresentar a nossa resposta, sendo eles:

(1) Barcelos e Abrahão (2006), que apontam para as habilidades de planejamento, criatividade e organização do trabalho na docência de LE, além das reflexões diárias que os docentes devem fazer para efetuar um bom trabalho;

(2) Almeida Filho (2006), que aponta para a importância das competências como sendo um construto teórico para a formação do bom professor de LE;

(3) Perrenoud (2000), que aponta algumas características como (a) estar aberto a aprender, (b) ser dinâmico e (c) ser criativo como sendo as novas competências de ensinar.

Concluímos que o bom professor de LE é aquele que possui competência linguístico-comunicativa, mas que também tem domínio do conteúdo, além de conhecimento de habilidades. A partir dos estudos realizados, percebemos que o bom professor de LE é aquele que enriquece o alunado, levando-o a um mundo de descobertas, a uma evolução de conhecimentos e acima de tudo é aquele que reflete sobre a sua própria prática.

\section{Referências Bibliográficas}

ALMEIDA FILHO, J. C. P. "Conhecer e desenvolver a competência Profissional dos professores de LE”. Contexturas: ensino crítico de língua inglesa. São Paulo: APLIESP, n.9. p. 9-19. 2006.

2005.

O professor de língua estrangeira em formação. Campinas, SP: Pontes Editora,

. Dimensões Comunicativas no Ensino de Línguas. Campinas, SP: Pontes Editora, 4 edição, 2007.

Linguística Aplicada - ensino de línguas e comunicação. Campinas, SP: Pontes Editora, 2005. 
BARCELOS, A. M. F. "Metodologia de pesquisa das crenças sobre aprendizagem de línguas: estado da arte". Revista Brasileira de Linguística Aplicada, v. 1, n. 1, p. 71-92, 2001.

Understanding teachers and students language learning beliefs in experience: A Deweyan Approach. Tese (Doutorado) - The University of Alabama, Tuscaloosa, 2000 .

- "Crenças e Ensino de Línguas: foco no professor, no aluno e na formação de professores". In: PESSOA, R. R.; SEBBA, M. A. Yasbec. Mudança nas teorias pessoais e na prática pedagógica de uma professora de inglês. Campinas, SP: Pontes Editora, 2006.

"Crenças e Ensino de Línguas: foco no professor, no aluno e na formação de professores". In: SILVA, K. A. da. O futuro professor de língua inglesa no espelho: crenças e aglomerados de crenças na formação inicial. Campinas, SP: Pontes Editora, 2006.

. "Crenças e Ensino de Línguas: foco no professor, no aluno e na formação de professores". In: BASSO, Edcleia A. Quando a crença faz a diferença. Campinas, SP: Pontes Editores, 2006.

BARCELOS, A. M. F. "Crenças sobre aprendizagem de línguas, Linguística aplicada e ensino de línguas”. Linguagem \& Ensino, v. 7, n. 1, p. 123-156. 2004.

BLATYTA, D. F. Estudo da reação dialógica entre a conscientização teórica e o habitus didático de uma professora num percurso de mudança da sua abordagem de ensinar. Dissertação de Mestrado em Linguística Aplicada. Instituto de Estudos da Linguagem, Unicamp, Campinas, 1995.

CARDOSO, R. C. T. "A dinâmica da sala de aula". Contexturas: ensino crítico de língua inglesa. São Paulo: APLIESP, n.5, p.79-96, 2000/2001.

CELANI, M. A. A.; MAGALHÃES, M. C. C. "Representações de professores de inglês como língua estrangeira sobre suas identidades profissionais: uma proposta de reconstrução". In: MOITA LOPES, L. P.; BASTOS, L. C (Orgs). Identidades: Recortes multi e interdisciplinares. Campinas, SP: Mercado de Letras, 2002.

CELANI, M. A. A. Professores e formadores em mudança: relato de um processo de reflexão e transformação da prática docente. Campinas, SP: Mercado das Letras, 2002.

CORTAZZI, M.; JIN, L. Bridges to learning: metaphors of teaching, learning and language. In: CAMERON, L.; LOW, G. (orgs.). Researching and applying metaphor. Cambridge: Cambridge University Press, pp. 149-176, 1999.

DEL RÉ, A. (Org.). Aquisição da linguagem: uma abordagem psicolinguística. São Paulo: Contexto, 2006. 
FERNANDES, C. S. Representações e construção da identidade do professor de inglês. Dissertação de Mestrado. Pontifícia Universidade Católica de São Paulo, 2006.

FILGUEIRAS dos Reis, M. R. "Características Metacompetentes do Professor de Prática de Ensino de Língua Estrangeira". Contexturas: ensino crítico de língua inglesa. São Paulo: APLIESP, 1992.

GARBUIO, L. M. Revelação e origens de crenças da teoria nformal implícita de professores de língua inglesa. Dissertação de Mestrado em Linguística Aplicada. Instituto de Estudos da Linguagem, Unicamp, Campinas, 2005.

Crenças sobre a língua que ensino: foco na competência implícita do professor de língua estrangeira. Campinas, SP: Pontes Editora, 2006.

GUIMARÃES, V.S. Formação de professores, saberes, identidades e profissão. Campinas, São Paulo: Papirus, 2006.

KALAJA, P.; BARCELOS, A. M. F. (Orgs). Beliefs about SLA: New research approaches. Kluwer Academic Publishers. Netherlands, 2003.

KRASHEN, S. Principles and Practice in Second Language Acquisition. University of Southern California, 1982. Disponível em: http://www.sdkrashen.com/Principles_and_Practice/index.html.

LEFFA, V. J. "O ensino de línguas estrangeiras no contexto nacional". Contexturas: ensino crítico de língua inglesa. São Paulo: APLIESP, n. 4, p. 13-24, 1999.

McLAUGHLIN, B. Theories of second language learning. London, Arnold, 1987.

OXFORD, R. L.; TOMLINSON, S.; BARCELOS, A.; HARRINGTON, C.; LAVINE, R. Z.; SALEH, A.; et al. Clashing metaphors about classroom teachers: toward a systematic typology for language teaching field. System, 26 (1), pp. 3-50, 1998.

PERRENOUD, Philippe. Pedagogia diferenciada: das intenções à ação. Porto Alegre: Artes Médicas, 2000.

POW, E. M. De Jazidas, Garimpos e Artífices: A formação fonológica do professor e sua identidade profissional. Dissertação de Mestrado em Linguística Aplicada e Estudos de Linguagem. Pontifícia Universidade Católica de São Paulo, 2003.

PRABHU, N. S. “The Dynamics of the Language Lesson”. Tesol Quarterly, 26(2), 1992.

. "There is no Best Method - Why?" Tesol Quarterly, 24-2, 1990.

SARDINHA, T. B. Metáfora. São Paulo: Parábola, pp. 63-85, 2010.

SILVA, K. A. "Crenças no ensino-aprendizagem e na formação de professores de línguas: Pontos e contrapontos". In: SILVA, K. A. (Org). Crenças, Discursos \& Línguagem. Volume II, Campinas, SP: Pontes Editores, 2011 (no prelo). 
. Crença e aglomerados de crenças de alunos ingressantes de Letras. Dissertação de Mestrado em Linguística Aplicada. Instituto de Estudos da Linguagem, Unicamp, Campinas, 2005.

SILVA, K. A. da; ROCHA, C. H.; SANDEI, M. de L. da. A importância do estudo das crenças na formação de professores de línguas. Ensino Crítico de Língua Inglesa. São Paulo, 2005.

TELLES, J. A. Being a Language Teacher: Stories of Critical Reflexion on Language and Pedagogy. Tese (Doutorado) - University of Toronto, 1996.

VIEIRA-ABRAHÃO, M. H. (Org.). Prática de Ensino de Língua Estrangeira: experiências e reflexões. Campinas, SP: Pontes Editora, Arte Língua, 2004.

WOODS, D. Teacher cognition in language teaching: beliefs, decision-making and classroom practice. Cambridge: Cambridge University Press, 1996. 